cold, according to the views of the practitioner; and, occasionally, fomentations.

Now, the tincture of iodine bas been em. ployed very extensively, both at the General Intirmary and in private practice, in this disease, and has been found a much more efficacious remedy than any of those in com. mon nse. It is necessary, however, to state, that no disease for which the iodine has been employed requires so much dis. cretion on the part of the surgeon as the one under consideration. If used too strong at first, or applied too frequently, it may give rise to inflammation of the integuments, and cause, or add to the puffiness of the soft parts external to the joint; but we have not known it in any one instance to aggravate the internal inflammation. We speak now more particularly of the knee-joint. The texture of the patient's skin must serve to guide the practitioner, in a great measure, respecting the strength of the tincture and the frequency of its application. It should be at first diluted to about half its strength, or more, if the skin be of a very delicate texture; and, if required, its strength may be gradually increased according to its effects. It is seldom that the remedy produces any irritation of the skin in otber parts of the body; and with regard to the knee, our remarks are intended more to put the practitioner upon his guard against what may happen, than to inform him of what will happen. Should any irritation or inflammation of the integuments occur, it will be very readily subdued by a simple evaporating lotion, composed of one part of spirit of wine to eight or ten of water.

The tincture, diluted, may be applied at once all over the inflamed joint, with perfect confidence that not only no mischief, but that good will be the result. But when the dis. ease has been pretty far advanced, and where the swelling has been considerable, we have generally preferred leeching the joint first, and then, a few hours after the bleeding had ceased, to apply the tincture. Whether by getting into the leech-bites the remedy exerts a greater influence on the internal vessels of the joint, we do not profess to know, but the fact is that the application of leeches, in this species of inflammation, previous to the employment of the tincture, tends greatly to assist the good effects of the latter. The remedy will generally require to be applied every day, for two or three times; then every other, or every third day, according to circumstances; the practitioner exercising his discretion according to the condition of the part, and the effect of each application. If, in the intermediate time of the applications, the part should acquire an increase of temperature-as it sometimes does very sud. denly, without any evident canse-it will be useful to lay over it a layer of rag soaked in spirit of wine, or in a simple spirit and water lotion. This application will not in- terfere with the repetition of the iodine But no lead or zinc lotion, or one medicated in any way, should be employed.

When the hip is the joint affected, leeches should be applied to the groin and behind the great trochanter; and after the bleeding has ceased, the whole of the upper part of the thigh, the hip, and the groin, should be well painted over with the tincture, of its full strength. The application, as in all other cases, shonld be repeated according to circumstances.

Having illustrated the principle and mode of application of the remedy, it is unneces. sary to occupy the time of the reader by a detdil of cases of this species of inflammation, for the doing so would be only a repetition of the same mode and principle al. ready just stated. It is also assumed, as a matter of course, that, in this disease, as well as in all other local affections, no general treatment calculated to assist in the sub. duction of the local malady has been neg. lected.

\section{CASE OF REMOVAL OF HAIF THE LOWER JAW.}

$B y$ R. O'Shaughnessy, Esq.

Kistomohun PaUl, ætat. 24, a remark. ably healthy-looking young man, presented himself at the Garranhatta Dispensary on the 2 lst of April last, requesting to be re. lieved from a tumour situated in the lower jaw. He says that it commenced about four years ago, with a gum-boil, near the second molar tooth, at the right side, which suppurated, and continued for some time to discharge a quantity of pus. The tooth soon became loose, and was extracted; his jaw then began to swell, and in a year or a year and a half, it gradually increased to near its present size; but it was not severely painful, or productive of very serious inconvenience, during its growth. He says that for the last two years he has not observed any alteration in it in point of size, but in consequence of the deformity it produces, he expressed himself willing to undergo any operation that may be deemed necessary for its removal.

On admission into hospital the tumour presented the following appearance:-It was about the size of two closed hands, nearly spherical in form, and extending as high up us the zygomatic arch, and as low down as about two inches below the base of the jaw; posteriorly it reached the mastoid process, and, anteriorly, extended as far as the external incisor tooth; within the nouth it forced the tongue upwards, and to the opposite side; and by its pressure on the alveolar processes of the superior maxilla of its own side, the teeth were considerably 
displaced, and the gums had a spongy ap- of the wonnd was strongly united, but a pearance, as if about to become affected small portion, about half au inch, near the with the same disease; the skin covering angle of the jaw, remained open for a conthe tumour was perfectly healthy and move- siderable time, and a quantity of saliva able. The surface of the tumour appeared of uniform density, and perfectly smooth, but as the finger was passed over it, in two or three places, it suak into a pit, which was evidently covered by a slight membrane, and surrounded by a sharp edge of bone; pressure on any part of the tumour produced no pain. The man bad tolerable up-and-down motion of the jaw, but no power of moving it laterally.

I performed the operation on the 25th of April, by first extracting the external incisor of the diseased side, and then making an incision through the lower lip, a little to the right of the mesial line; this incision I continued through the chin, and for two or three lines below it, and next carried an incision at a right angle from the lowest part of it, about two inches outwards, and to the right side. I was then able to separate the flap so formed, and, having bared the bone, I commenced to cut through it with the saw, finishing its division with Liston's forceps. I then continued the last iucision through the skin, along the base of the jaw, round its angle, and up as far as opposite the tube of the ear; this flap was reflected upwards, and the whole surface of the tumour exposed. (As I was separating the flap from the tumour I divided what appeared to be a cyst, in the latter, giving exit to a quantity of a clear watery fluid.) My next ubject was to separate the insertion of the ten poral muscle from the coronoid pro. cess, but this I had the greatest difficulty in accomplishing; from the manner in which that process was wedged in under the zy gomatic arch, there was no room, either from before or behind, to introduce the blade of the knife for that purpose, so that it was not till I had separated the tumour from the tongue and soft palate, and also loosened the articulation, by dividing the ligaments, that I was able to free it from this strong attachment; but that being accomplished, there was no further obstacle to the remuval of the diseased mass.

While dissecting the tumour from the back part of the mouth I felt I was in considerable danger, as I could distinctly feel the internal carotid artery beating strongly close to it, and that if I cut incautiously I in all probability should divide it. There was but little blood lost during the operation, though it was necessary to tie five or six arteries afterwards. In about two hours after the operation I closed the woynd, with two points of twisted and fonr interrupted sutures, put a piece of wet lint on the part, and left orders that it should be kept muist. On the third day I took out the pins, the wound through the lips being healed. In bix days after the operation the greater part fowed from it; before his discharge from hospital, horever, it had completely closed up. He had not a single disagreeable symptom, or the slightest fever, after the operation; though it may not be uninteresting to mention that the temperature at the time of the operation in the hospital was $90^{\mathrm{C}}$, and was not up to the date of his discharge, $3 \mathrm{rd}$ of June, lower than $90^{\circ}$ during the day.

The tumour, after maceration, was found to be a hollow shell of bone, containing in its centre a quantity of a gelatinous and tuid substance, and a few particles of bone like pieces of honeycomb. The coronoid process is hollowed ont, like the rest of the bone, and so thick that it must have completely filled the lower part of the temporal fossa, which accounts for the difficulty I experienced when trying to divide the temporal muscles; the natural appearance of the neck of the jawbone is also lost, and the condyle is only to be distinguisbed by the cartilage which covers it.

I think it is a great object not to divide the jaw at the symphysis if possible, as, in the first place, by cutting external to it, as I did, the roundness of the chin is preserved; and, in the next place, the insertion of the anterior belly of the digastric muscle is uninjured, which must serve like a guy in regulating the motion of the bone, and prevent its being drawn to the opposite side.

The poor man left the hospital quite delighted with his improved appearance; indeed, to look at him, no one would ever suppose that any portion of his jaw had been removed.-Calculta Quarterly Jokrnal, No. VI.

Sir S. Garth. - Many amuging anecdotes are recorded of this eminent poet and physician. On one occasion, when he met the members of the celebrated Kit.Kat Club, he declared that he must soon be cone, having many patients to attend, but on some excellent wine heing placed on the table, and the conversation becoming interesting and animated, the doctor soon forgot his professional engagements. His friend. Sir Richard Steel, however, thought it his duty to remind the doctor of his poor patients. Garth immediately pulled out his list, upon which were fifteen names. "It is no great matter whether I see them to-night or not," saili be, "for nine of them have sucb bad constitutions that all the physicians in the world can't save them; and the other six bave such good constitutions that all the physicians in the world can't kill them."Physic and Physicians. 